\title{
Correlation between dewatering index and dewatering performance of three mechanical dewatering devices
}

\author{
Jill Ruhsing Pan ${ }^{\mathrm{a}}$, Chihpin Huang, ${ }^{\mathrm{a} *}$, Minyih Cherng ${ }^{\mathrm{a}}$, Kung-Cheh Li ${ }^{\mathrm{b}}$, Cheng-Fang Lin ${ }^{\mathrm{b}}$ \\ anstitute of Environmental Engineering, National Chiao Tung University, Hsinchu, 30039 Taiwan, ROC \\ ${ }^{\mathrm{b}}$ Graduate Institute of Environmental Engineering, National Taiwan University, Taipei, 106 Taiwan, ROC
}

\begin{abstract}
Efficient sludge conditioning can improve sludge dewatering characteristics and promote the separation of flocs from the liquid phase to achieve a high solid content. To optimize this process, a reliable dewatering index must be established. Although numerous researches investigated sludge conditioning, few are devoted to the correlation between the conditioning index and the dewatering efficiency. In this study, sludges were conditioned with both synthetic and natural polymers, and their dewatering characteristics after three different mechanical dewatering devices, the filter press, belt press, and the centrifuge, were compared. The result shows that the traditionally used dewatering index may not reflect sludge conditioning properly. Correlation between sludge conditioning indices and dewaterability depends upon both the type of sludge and the means of sludge conditioning and dewatering. It is therefore concluded that dewatering index must be properly chosen for optimum sludge conditioning.
\end{abstract}

(c) 2002 Elsevier Science Ltd. All rights reserved.

Keywords: Sludge conditioning; Dewatering index; Sludge dewatering; CST; SRF

\section{Introduction}

Because of the higher standard and more stringent government regulations for drinking water, annual production of sludge from water treatment plants (WTPs) is increasing rapidly. Most WTPs utilize sludge conditioning to improve sludge dewatering. To optimize sludge conditioning, sludge dewatering characteristics such as capillary suction time (CST), specific resistance to filtration $(S R F)$, zeta potential (ZP), and rheological properties, must be carefully monitored. CST represents the filterability and SRF represents the permeability. Although CST has many advantages, such as easy operation, it is far from realistic since no pressure is applied. Over-dosing of sludge conditioning by polymers as a result of CST measurement has been reported

*Corresponding author. Tel: + 886-3-572-6463; fax: +8863-572-5958.

E-mail address: cphuang@cc.nctu.edu.tw (C. Huang).
(Wu et al., 1997). The process of $S R F$, on the other hand, is similar to the operation of a filter press. Large errors are generally encountered when dealing with sludge of low solid content.

The correlation between the variations in SRT and the CST measurement for sludge has been observed in several studies. Tay and Jeyaseelan (1997a,b), in studying the conditioning of oil-containing sludge with fly ash and lime and aluminum salt, discovered that CST and $S R F$ were highly related. Christensen et al. (1993) showed that there is a relationship between the CST and $S R F$ :

$C S T=c_{1} \times S R F \times \mu_{f} \times w+c_{2} \times \mu_{f}$

in which $c_{1}$ and $c_{2}$ are coefficients related to CST, $\mu_{f}$ is the viscosity of the filtrate, and $w$ is the solid content in unit volume of the filtrate. They suggested that the resistance value came from two sources, the sludge and 
the equipment. In an AWWA publication in 1998, a series of experiments were performed to evaluate the dewatering capacities of fresh water sludge with CST, $S R F$ and TTF (time to filter). It was concluded that there was a good relationship among dewatering indices. However, there was no significant relationship between the dewatering index and the physical properties of the sludge, such as the particle size. In studying sludge conditioning with organic polymers, they found that the optimal dosage determined from $S R F$ was higher than that from CST. Two measurements were similar in quantity when sludges were conditioned with inorganic conditioners (Christensen et al., 1993). Later, other researchers discovered that in sludge conditioning with polymers, optimal dosages determined from the CST test were higher than those from the SRF test (Wu et al., 1997; Papavasilopoulos, 1997; Papavasilopoulos and Bache, 1998).

Various studies have shown that the type of sludge and dewatering device affect the efficiency of sludge dewatering (Chu and Lee, 1999; Rehmat et al., 1997; Nellenschulte and Kayser, 1997). Filter press, belt press, and centrifuge are the most commonly used dewatering equipment. Rehmat et al. (1997) used a laboratory-scale filter press and a belt press to dewater activated sludge and discovered that solid contents of the sludge cakes produced from both devices were approximately the same. By applying pressure from 3000 to $20000 \mathrm{kPa}$ on a filter press, Chu and Lee (1999) discovered a three-stage behavior of sludge dewatering depending upon the type of water. Many researchers have focused on improving sludge dewatering by searching for the optimal sludge conditioner and dosage. However, they ignore the critical role of the dewatering device and its effect on dewatering index. In this study, we studied the dewatering characteristics of sludges from different sources under three mechanical dewatering devices in an attempt to investigate the correlation between the sludge dewatering index and dewaterability.

\section{Materials and methods}

Both fresh water sludge and biological activated sludge were used in this study. The fresh water sludge was collected from the concentration basin at the HsinChu Water Treatment Plant in Hsin-chu, Taiwan. In this plant, polymeric aluminum chloride $(\mathrm{PACl})$ is used in the coagulation. The activated sludge samples were obtained from the wastewater treatment plant of the Neili Bread Plant, President Enterprise Co., Taoyuan, Taiwan. The characteristics of the raw sludge samples were analyzed and summarized in Table 1 . The analyses were performed in the laboratory within $2 \mathrm{~h}$ of sampling to prevent the aging process, while all tests were finished within 2 days. Sludge samples were divided into two parts. One part was for experiments performed under
Table 1

Characteristics of raw activated and fresh water sludge samples

\begin{tabular}{|c|c|c|c|c|c|}
\hline Sludge & $\begin{array}{l}\text { Original } \\
\mathrm{PH}\end{array}$ & $\begin{array}{l}\text { TS } \\
(\%)\end{array}$ & $\begin{array}{l}\text { VS } \\
(\%)\end{array}$ & $\begin{array}{l}\text { VS/TS } \\
(\%)\end{array}$ & $\mathrm{ZP}(\mathrm{mv})$ \\
\hline $\begin{array}{c}\text { Activated } \\
\text { sludge }\end{array}$ & $\begin{array}{l}6.82- \\
7.12\end{array}$ & $\begin{array}{l}0.49- \\
0.75\end{array}$ & $\begin{array}{l}0.41- \\
0.65\end{array}$ & $83-87$ & $\begin{array}{l}-15.4 \text { to } \\
-27.6\end{array}$ \\
\hline $\begin{array}{c}\text { Fresh water } \\
\text { sludge }\end{array}$ & 7.05 & 6 & 0.2 & 3 & -22 \\
\hline
\end{tabular}

room temperature. The other part was stored in a freezer set at $-4{ }^{\circ} \mathrm{C}$ for $24 \mathrm{~h}$, followed by thawing for another $12 \mathrm{~h}$ under room temperature. The raw and cold-treated sludge samples were referred to as the 'original sludge' and the 'cold-treated sludge'.

Cationic polyelectrolyte (Polymer-PC-325) and chitosan were applied for separate sludge conditioning experiments. Polymer-PC-325 was obtained from the Taiwan Polymer Company. It is a copolymer of acrylamide and diallyldimethyl-amonium chloride, with an average molecular weight of $1.1 \times 10^{7}-1.2 \times 10^{7}$, and a $25 \%$ charge density. Polymer solution $(0.1 \% \mathrm{w} / \mathrm{w})$ was prepared according to methods proposed by the polymer manufacturer. Chitosan was obtained from the Bioscience Company.

Various amounts of Polymer-PC-325 were added to 11 of sludge sample. After mixing at 100 r.p.m. for 1 min, sludge dewatering characteristics of the conditioned sludge were determined. The CST was determined using a Triton CST Apparatus Model 200 with a Whatman no. 17 paper filter. A standard Buchner funnel apparatus with a 9-cm funnel was used for the $S R F$ determinations. The detail experimental procedures for CST and SRF measurements can be found in the study of $\mathrm{Wu}$ et al. (1997).

Three laboratory-scale mechanical dewatering devices, namely a filter press, belt press and centrifuge, were adopted for expressing water from conditioned sludge samples. The pressure applied on the belt press and filter press was $10 \mathrm{~kg} / \mathrm{cm}^{2}$, and the centrifuge was operated at a speed of 1200 r.p.m. for $60 \mathrm{~s}$ to obtain equivalent performance. The dewatering efficiency was represented by the water content, which was determined from the difference in the weight of the pressed sludge cakes before and after drying at $105{ }^{\circ} \mathrm{C}$ for $24 \mathrm{~h}$.

\section{Results and discussion}

Activated sludge samples were conditioned with various concentrations of Polymer-PC-325 and chitosan. Optimal dosages corresponding to each mechanical dewatering device were determined from the CST values. Sludges obtained from the optimal conditioning were divided into three parts and dewatered with a belt press, filter press and centrifuge. Water contents of the 
Table 2

Water contents (\% wt.) of optimal conditioned activated sludge cakes under various mechanical dewatering procedures

\begin{tabular}{lllll}
\hline Sludge conditioner & $\begin{array}{l}\text { Activated } \\
\text { sludge }\end{array}$ & $\begin{array}{l}\text { Belt } \\
\text { press }\end{array}$ & $\begin{array}{l}\text { Filter } \\
\text { press }\end{array}$ & Centrifuge \\
\hline Chitosan & Original & 86 & 86 & 84 \\
& Cold-treated & 88 & 87 & 85 \\
Polymer-PC-325 & Original & 85.5 & 85.5 & 84 \\
& Cold-treated & 87 & 86.5 & 85.5 \\
\hline
\end{tabular}

sludge cakes generated from the three dewatering processes are summarized in Table 2. The water content was reduced from the original $99 \%$ in the raw sludge to between $84 \%$ and $88 \%$ in the pressed sludge cakes. No significant difference in conditioning efficiency was observed between chitosan and Polymer-PC-325. Coldtreatment did not improve the dewaterability of the activated sludge. Although the dewatering by centrifuge seems to be slightly better than the other two dewatering devices, this difference may be caused by experimental error because of the relatively small scale involved.

To truly reflect the efficiency of sludge conditioning, the dewatering index monitored must have a good correlation to the final water content of the sludge cakes. In this section, original and cold-treated sludge samples were conditioned with various amounts of chitosan and Polymer-PC-325. CST and SRF of each conditioned sludge, were analyzed against the corresponding water content of the sludge cake. Their correlation coefficients are reported in Table 3. A higher value of correlation coefficient means that the dewatering index can better represent the final product of sludge conditioning. Table 3 shows that more consistent results are found among activated sludge samples conditioned with chitosan. In general, the dewaterability through centrifuge dewatering can be best represented by the CST values, because in both operations no pressure is exerted on flocs. CST is not a reliable index for filter press or the belt press. This is because pressure is exerted on flocs when a belt press and filter press are used for dewatering. Since no pressure is given in the process of CST measurement, the CST value cannot reflect the strength of the floc and therefore, the filterability of the sludge. On the other hand, $S R F$ is a better option for filter press dewatering because of the similar filtration behavior. Very inconsistent results are associated with belt press dewatering. No conclusion can be made for the belt press, mostly due to the great experimental error involved in the scraping of sludge cake from the belt. It is also observed that when the sludge sample was pretreated with low-temperature, the dewaterability became unpredictable especially by $C S T$, as evidenced by the low correlation coefficients. This is probably due to the destruction of the floc structure in
Table 3

Correlation coefficients of CST and SRF vs. dewaterability of mechanical dewatering devices for activated sludges subjected to various conditioning methods

\begin{tabular}{cllll}
\hline $\begin{array}{l}\text { Sludge } \\
\text { conditioner }\end{array}$ & $\begin{array}{l}\text { Activated } \\
\text { sludge }\end{array}$ & $\begin{array}{l}\text { Belt } \\
\text { press }\end{array}$ & $\begin{array}{l}\text { Filter } \\
\text { press }\end{array}$ & Centrifuge \\
\hline CST & & & & \\
\multicolumn{1}{c}{ Chitosan } & Original & 0.69 & 0.94 & 0.96 \\
& Cold-treated & 0.14 & 0.73 & 0.79 \\
PC-325 & Original & 0.64 & 0.31 & 0.88 \\
& Cold-treated & 0.08 & 0.31 & 0.66 \\
SRF & & & & \\
Chitosan & Original & 0.74 & 0.97 & 0.58 \\
& Cold-treated & 0.43 & 0.89 & 0.66 \\
PC-325 & Original & 0.75 & 0.89 & 0.39 \\
& Cold-treated & 0.52 & 0.89 & 0.21 \\
\hline
\end{tabular}

the freeze/thaw process. The much higher correlation coefficients between CST and chitosan-treated activated sludge samples suggest that more consistent results occur between the dewatering index and the more effectively conditioned sludge.

Fresh water sludge contains less organic materials, with more solid content. Similar analyses were performed on the chitosan-conditioned fresh water sludge. The entire experiments were conducted at room temperature. The water content of sludge cake and correlation coefficients of CST and SRF vs. water contents of sludge cakes are listed in Table 4. Sludge cakes from all three dewatering procedures retain much less water. Coefficients fall into a much narrower range, from 0.73 to 0.87 , than those of the activated sludge samples.

\section{Conclusions}

The pressed cakes of optimally conditioned activated sludge contained $84-87 \%$ water regardless of the means of dewatering. Correlation analysis showed that a more consistent result was found between the dewatering index and the more effectively conditioned sludge. The dewaterability of sludge by means of centrifuge dewa-

Table 4

Water content of sludge cake and their correlation coefficients to $C S T$ and $S R F$ for three mechanical dewatering devices

\begin{tabular}{llll}
\hline & $\begin{array}{l}\text { Belt } \\
\text { press }\end{array}$ & $\begin{array}{l}\text { Filter } \\
\text { press }\end{array}$ & Centrifuge \\
\hline Water content of sludge cake & $64 \%$ & $64 \%$ & $64 \%$ \\
Correlation coefficient & & & \\
$\quad$ CST & 0.77 & 0.73 & 0.8 \\
SRF & 0.78 & 0.87 & 0.84 \\
\hline
\end{tabular}

Sludge samples consist of fresh water sludge subjected to chitosan conditioning. 
tering can be best represented by $C S T$ values due to the similar mechanism of operation. $S R F$ is a practical index for filter press dewatering, because of their similar filtration behavior. No conclusion can be made for the belt press. The dewaterability of samples that went through a freeze/thaw process became unpredictable especially by $C S T$, probably due to the destruction of floc structure. Although no universal dewatering index exists, selecting a good dewatering index is a challenging, yet a critical procedure for optimizing sludge conditioning.

\section{References}

Christensen, J.R., Sorensen, P.B., Christensen, G.L., Hansen, J.A., 1993. Mechanisms for overdosing in sludge conditioning. J. Environ. Eng. 119, 159-171.

Chu, C.P., Lee, D.J., 1999. Three stages of consolidation dewatering of sludge. J. Environ. Eng. 125, 959-965.
Nellenschulte, T., Kayser, R., 1997. Change of particle structure of sewage sludges during mechanical and biological processes with regard to the dewatering result. Water Sci. Technol. 36 (4), 293-306.

Papavasilopoulos, E.N., 1997. Viscosity as a criterion for optimum dosing of polymers in waterworks sludge. J. CIWEM 11, 217-224.

Papavasilopoulos, E.N., Bache, D.H., 1998. On the role of aluminum hydroxide in the conditioning of an alum sludge. Water Sci. Technol. 38 (2), 33-40.

Rehmat, T., Branion, R., Duff, S., Groves, M., 1997. A laboratory sludge press characterizing sludge dewatering. Water Sci. Technol. 35 (2-3), 189-196.

Tay, J.H., Jeyaseelan, S., 1997. Conditioning of oily sludges with municipal solid wastes incinerator fly ash. Water Sci. Technol. 35 (8), 231-238.

Tay, J.H., Jeyaseelan, S., 1997. Comparison of lime and alum as oily sludge conditioners. Water Sci. Technol. 36 (12), 117-124.

Wu, C.C., Huang, C.P., Lee, D.J., 1997. Effect of polymer dosage on alum sludge dewatering characteristics and physical properties. Colloids Surf. A 122, 89-96. 